\title{
A distinct form of spondyloepimetaphyseal dysplasia with multiple dislocations
}

\author{
Christine M Hall, Nursel H Elçioglu, Donald G Shaw
}

^Present address: Department of Genetics, Cerrahpasa Medical School, Istanbul, Turkey.

Received 1 September 1997 Revised version accepted for publication

31 December 1997

\begin{abstract}
Department of Radiology, Great Ormond Street Hospital for Children NHS Trust, London WCiN 3JH, UK C M Hall

N H Elçioglu*

D G Shaw

Correspondence to: Dr Hall.

Abstract

Three unrelated patients with identical radiological features are presented. Hypotonia was noted at birth and one patient was diagnosed as having congenital fibre type disproportion in the neonatal period. Later muscle biopsies, however, were entirely normal. All patients, now in their teens and twenties, are of normal intelligence, show striking epiphyseal and metaphyseal changes of the long bones, and have joint laxity and multiple dislocations of large joints, which are particularly incapacitating at the knees. These three cases represent a sporadic, previously unreported skeletal dysplasia with spondyloepimetaphyseal distribution and multiple large joint dislocations.

$(\mathcal{O}$ Med Genet 1998;35:566-572)
\end{abstract}

Keywords: spondyloepimetaphyseal dysplasia; joint dislocations

The term "spondyloepimetaphyseal dysplasia" (SEMD) embraces a large group of disorders which are characterised by involvement of the epiphyses, metaphyses, and vertebral bodies and are distinguished on the basis of clinical and radiological features.

A review of 450 undiagnosed cases on the Skeletal Dysplasia Registry of the Department of Radiology, Great Ormond Street Hospital for Children NHS Trust identified three unrelated children with virtually identical clinical and radiological features. We believe they represent a unique form of SEMD.

\section{Case reports}

CASE 1

This female infant presented at birth with a dislocated hip which was treated conservatively. Subsequently joint laxity was pronounced and her knees became unstable. She was noted to be very short at the age of 6 years but no measurements were recorded. Her skin appeared to be velvety and floppy over the back of the hands although elasticity was normal. There was no excessive bruising and healing was normal. The sclerae, teeth, and hair were normal. Her mother had similar skin changes resulting in premature ageing of her face with
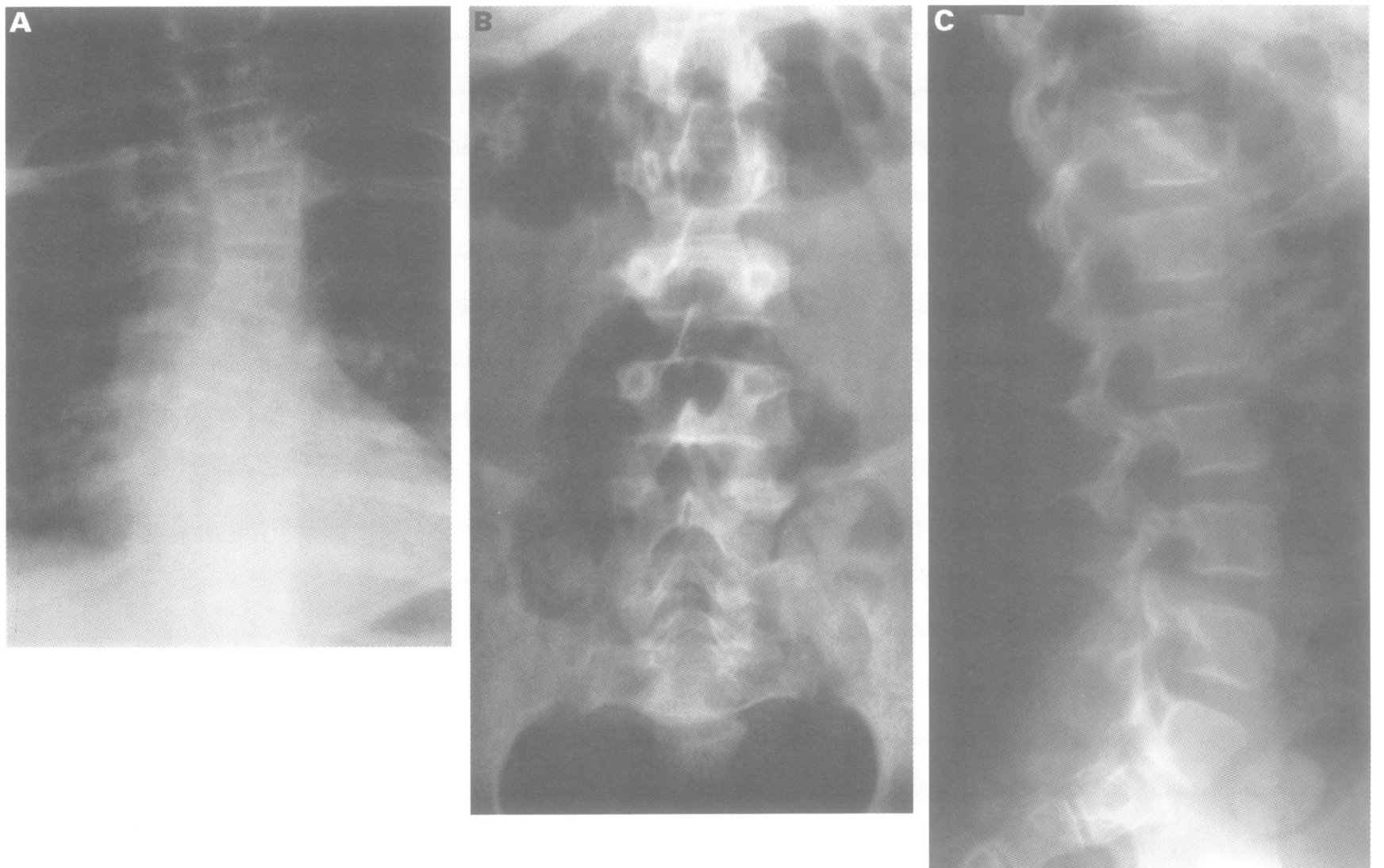

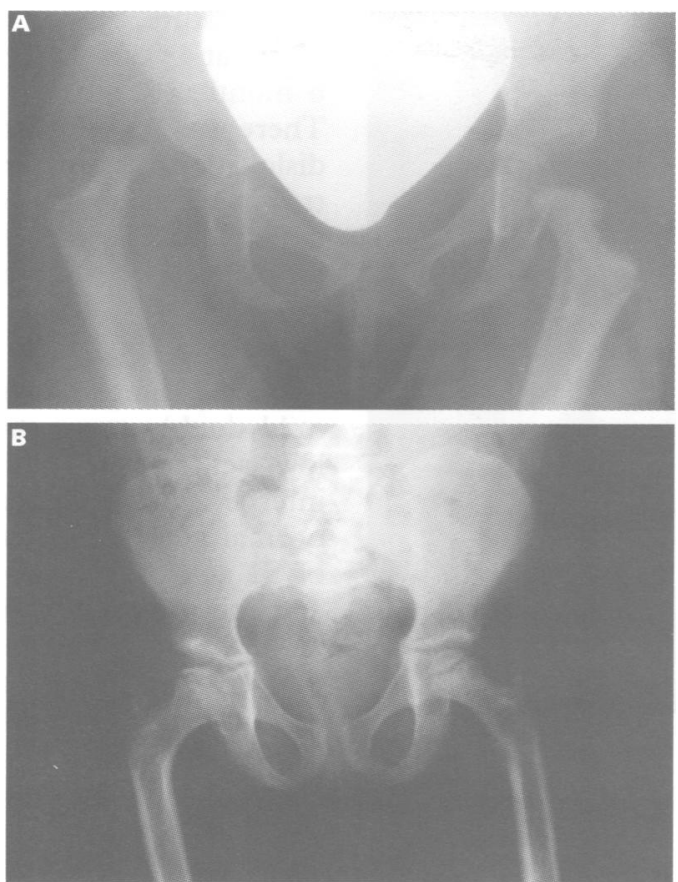

Figure 2 Hips of case 1. (A) Aged 2 years. Right hip dislocated with a dysplastic acetabulum. Femoral capital epiphyses absent. Femoral necks attenuated. (B) Aged 7 years. Small flattened capital femoral epiphyses. Fragmentation on right.

loose cheeks, but joints were normal. This suggested a dominantly inherited connective tissue disorder and Ehlers-Danlos syndrome was suggested. Skeletal radiographs of the child,

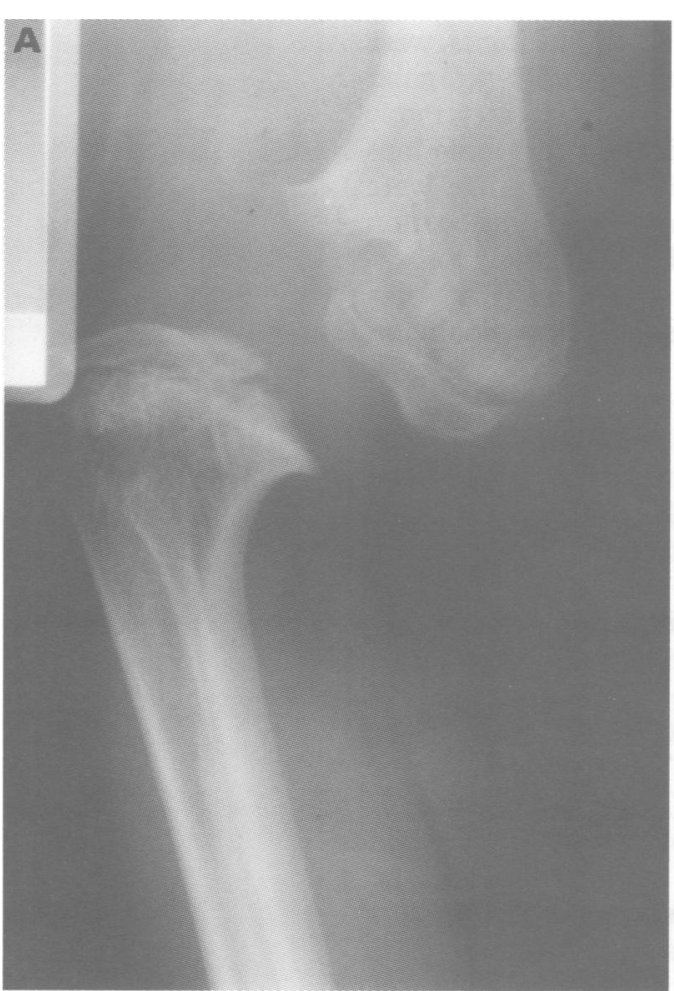

however, showed features of a skeletal dysplasia with strikingly severe epiphyseal and metaphyseal changes. She developed a scoliosis. By 8 years of age she had striking joint laxity and her knees were so unstable that rigid callipers were required for standing and walking.

\section{Radiolographic findings}

Spine. At the age of 7 years, there was a double curve scoliosis in the thoracic region (fig 1A). There was progressive caudal narrowing of the interpedicular distances, L5 was low set between the iliac wings, and there was minor spinal dysraphism of S1 (fig 1B). The lumbar vertebral bodies had mild vertebral end plate irregularity with posterior scalloping (fig 1C).

Hips. At the age of 2 years, the right acetabulum was sloping and irregular and the right hip dislocated. The femoral necks were narrow and tapered with no ossification of the capital femoral epiphyses. The femoral metaphyses showed irregular ossification and the diaphyses were disproportionately wide with some cortical thickening. The ischia were tapered (fig $2 \mathrm{~A}$ ). At the age of 3 years, small, flattened, and irregularly ossified capital femoral epiphyses were present. The femoral necks remained slender and elongated. The right acetabulum was better developed with no dislocation. By the age of 7 years, fragmentation of the right capital femoral epiphysis most probably represented superimposed changes of ischaemic necrosis secondary

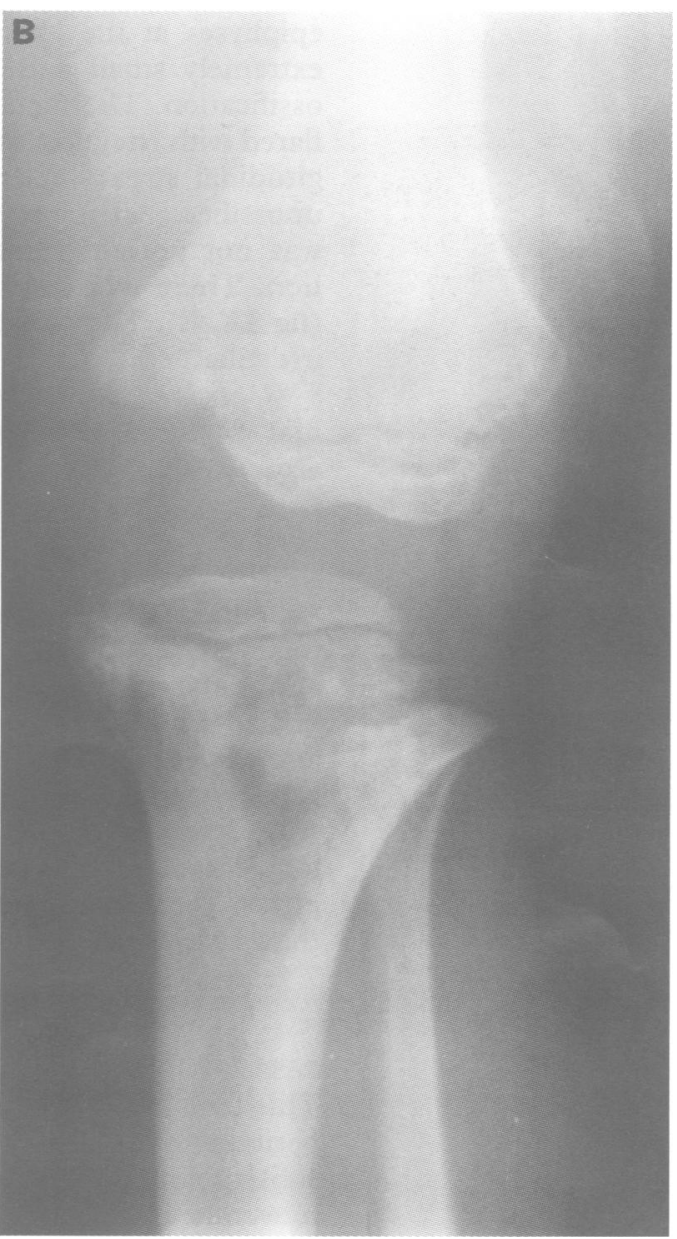




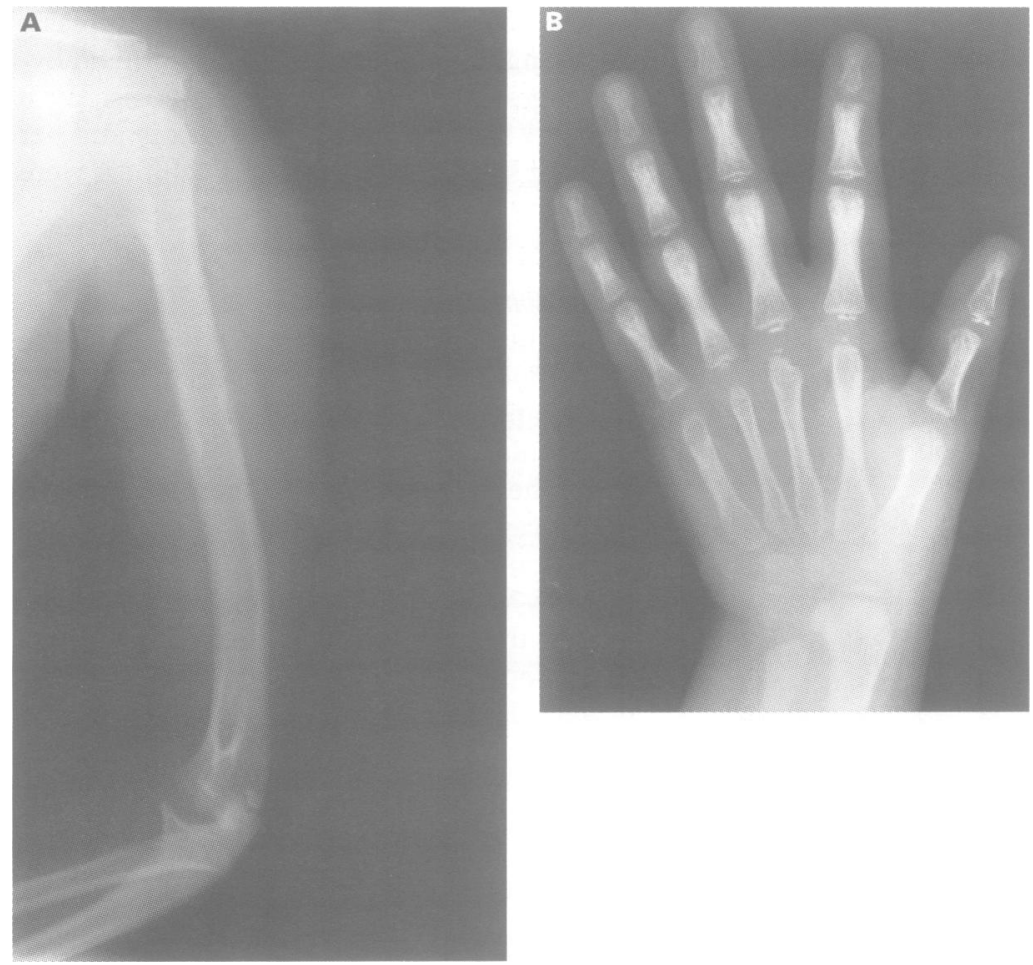

Figure 4 Upper limbs of case 1 aged 7 years. (A) Radial head dislocated. Humeral epiphyses small, flattened, and irregular. (B) Metacarpals gracile. Phalanges long and slender with broad, squared distal ends. Tufus prominent. Carpal bones small with delayed retardation. Overall small carpus. Epiphyses of the radius and phalanges small, irregular, flattened, and dense. Short distal ulna. short stature, below the 3th centile, measuring $77 \mathrm{~cm}$ at 4 years 5 months and $85 \mathrm{~cm}$ at 5 years 6 months. She had mild midface hypoplasia. There was no relevant family history. The hip dislocations did not respond to conservative treatment in abduction harness and bilateral upper femoral osteotomies and a right acetabuloplasty were performed.

\section{Radiographic findings}

Spine. At the age of 6 years there was a very mild double curve thoracic scoliosis. L5 was low set between the iliac wings and the interpedicular distances failed to widen in the normal manner. There was spinal dysraphism of S1 and S2. There was posterior scalloping and end plate irregularity of the vertebral bodies in the lumbar region. In the thoracic region the vertebral bodies had a "pear shaped" configuration with some posterior constriction (fig 5). In addition, the thorax was broad and the upper humeral epiphyses were small and flattened. The skull showed quite pronounced convolutional markings but normal sutures at the age of 6 years.

Pelvis. At the age of 3 years, both hips were dislocated. There was delayed ossification of both capital femoral epiphyses. The femoral necks were long, slender, and tapering with irregular metaphyses. The acetabula were

to treatment of the hip dislocation The iliac wings appeared normal (fig $2 \mathrm{~B}$ ).

Lower limbs. At the age of 8 years, the epiphyses at the knee and ankle joints were extremely small and flattened with irregular ossification. The metaphyses were moderately flared with irregular ossification and some longitudinal streaky sclerosis. The patellae were unossified. All joints where frank dislocation was not present showed significant subluxation. There was dislocation at the right knee (fig $3 \mathrm{~A}, \mathrm{~B}$ ). The tarsal centres were small and irregular.

Upper limbs. At the age of 7 years, the proximal humeral epiphyses and the epiphyses around the elbow joints were small and flattened. There was dislocation of the radial head (fig 4A) and the distal end of the ulna was short. The overall size of the carpus was extremely small and the individual carpal centres were small. The metacarpals were slender and undermodelled. The middle and proximal phalanges were slender with slightly expanded and squared distal ends. The distal phalangeal tufts were prominent. There were multiple small ivory epiphyses of the phalanges and metacarpals. Phalangeal and metacarpal epiphyses corresponded to a standard of no more than 1 year 6 months at a chronological age of 7 years (fig 4B).

CASE 2

This female patient presented in the newborn period with dislocated hips and hypotonia and subsequently developed limitation of joint movements. Initial muscle biopsies suggested a type I fibre disproportion myopathy but this was not confirmed. She had proportionate

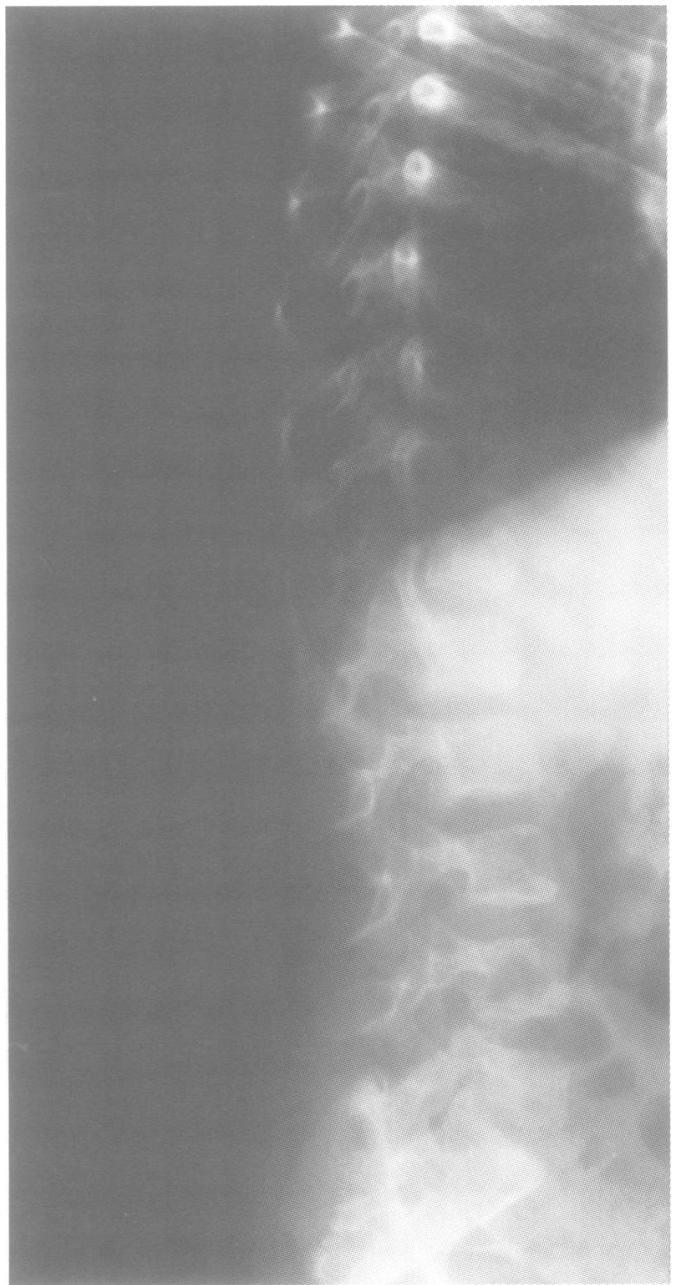

Figure 5 Spine of case 2 aged 6 years. Dorsal vertebral bodies "pear shaped". Posterior scalloping of the lumbar vertebral bodies. 


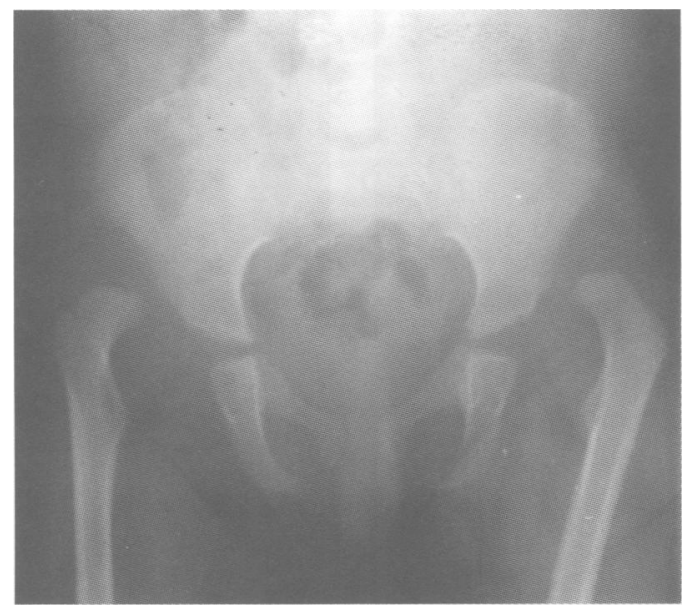

Figure 6 Hips of case 2 aged 3 years. Bilateral dislocation of the hips and slender femoral necks. Femoral capital epiphyses are only just visible. Medial ends of ischia tapered; shallow acetabula. Narrow lower lumbar interpedicular distances and spinal dysraphism.

shallow, sloping, and irregular (fig 6). Following treatment, by the age of 9 years, the position was improved but the capital femoral epiphyses remained small and flattened.

Lower limbs. At the age of $6^{1 / 2}$ years, there was a genu valgum deformity. The metaphyses were flared with irregular ossification and some marginal streaky sclerosis. The epiphyses were extremely small and flattened with deficient ossification laterally. Small marginal spurs were present. The patellae were unossified (fig 7A). Similar metaphyseal and epiphyseal changes were present at the ankles (fig 7B).

Hands. At the age of $4 \frac{1}{2}$ years, the metacarpals were gracile and undermodelled. The distal ends of the middle phalanges were relatively wide and flattened.The size of the carpus was small with only two small carpal centres ossified. Bone maturation was severely retarded. Phalangeal epiphyseal bone maturation corresponded to about 1 year of age at this time (fig 8).

\section{CASE 3}

This male patient presented at birth with marked joint laxity and was thought to have a form of Ehlers-Danlos syndrome although he did not have the classical skin changes. He was

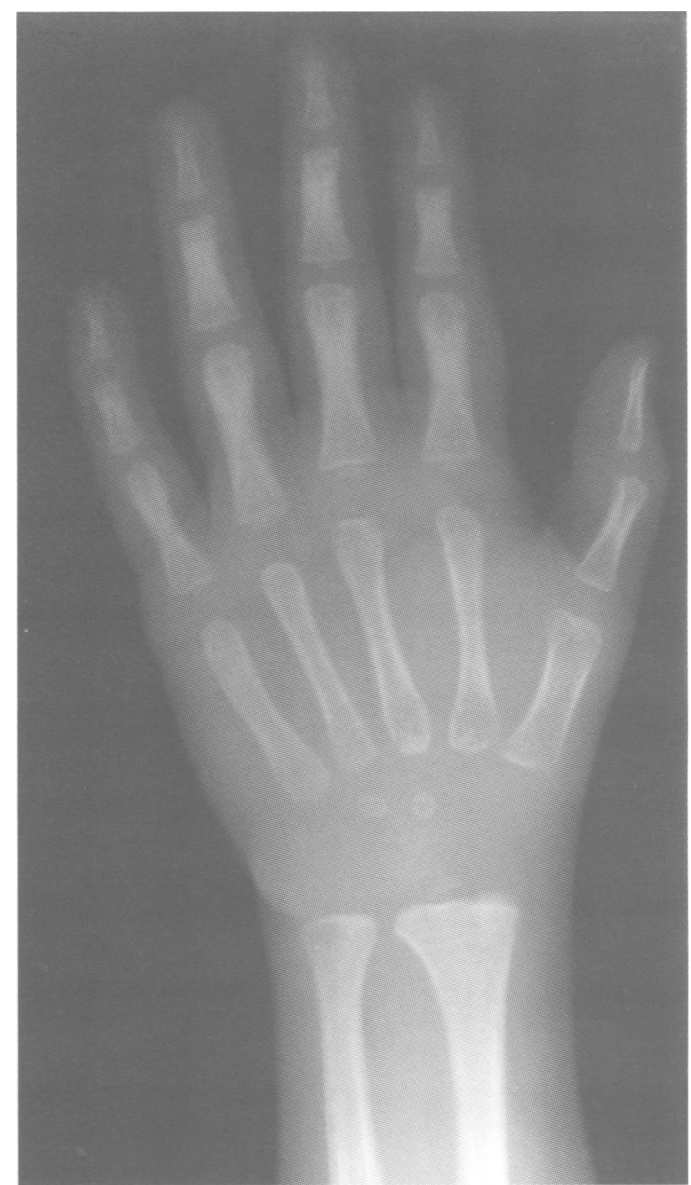

Figure 8 Hand of case 2 aged $4^{1 / 2}$ years. Metacarpals slender. Small carpus and carpal bones. Epiphyses small and flattened. Distal ends of proximal and middle

phalanges broad and squared. Delayed maturation.

short but measurements were not available. The family history was unremarkable.

\section{Radiographic findings}

Spine. At the age of 4 years, there was a very mild triple curve scoliosis. L5 was low set between the iliac wings and there was spinal dysraphism of $\mathrm{S} 1$ and S2. There was progressive caudal narrowing of the interpedicular distances (fig 9A). There was a very mild thoracolumbar kyphosis with adjacent disc space narrowing and vertebral end plate irregularity. There was mild anterior and posterior scalloping of the
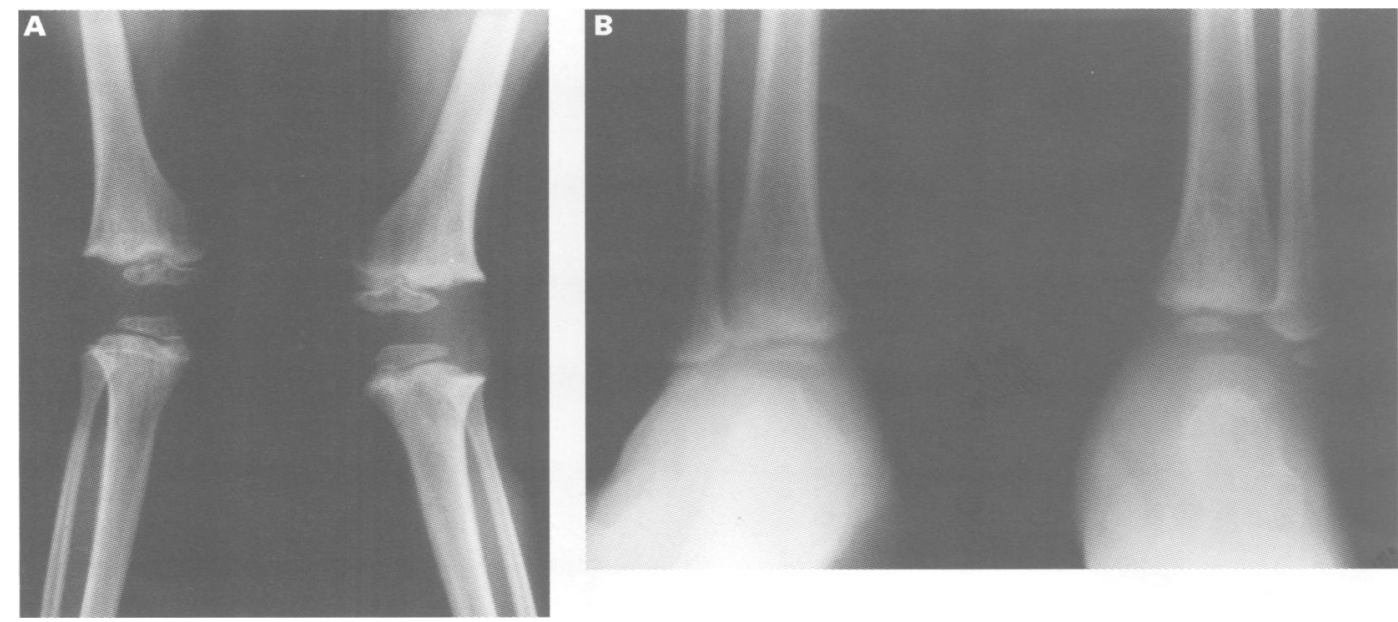

Figure 7 (A,B) Lower limbs of case 2 aged 61/2 years. Epiphyses small, flattened, and irregular. Metaphyseal flaring and streaky sclerosis and irregularity with spur formation. Genu valgum. Absent patellae. 

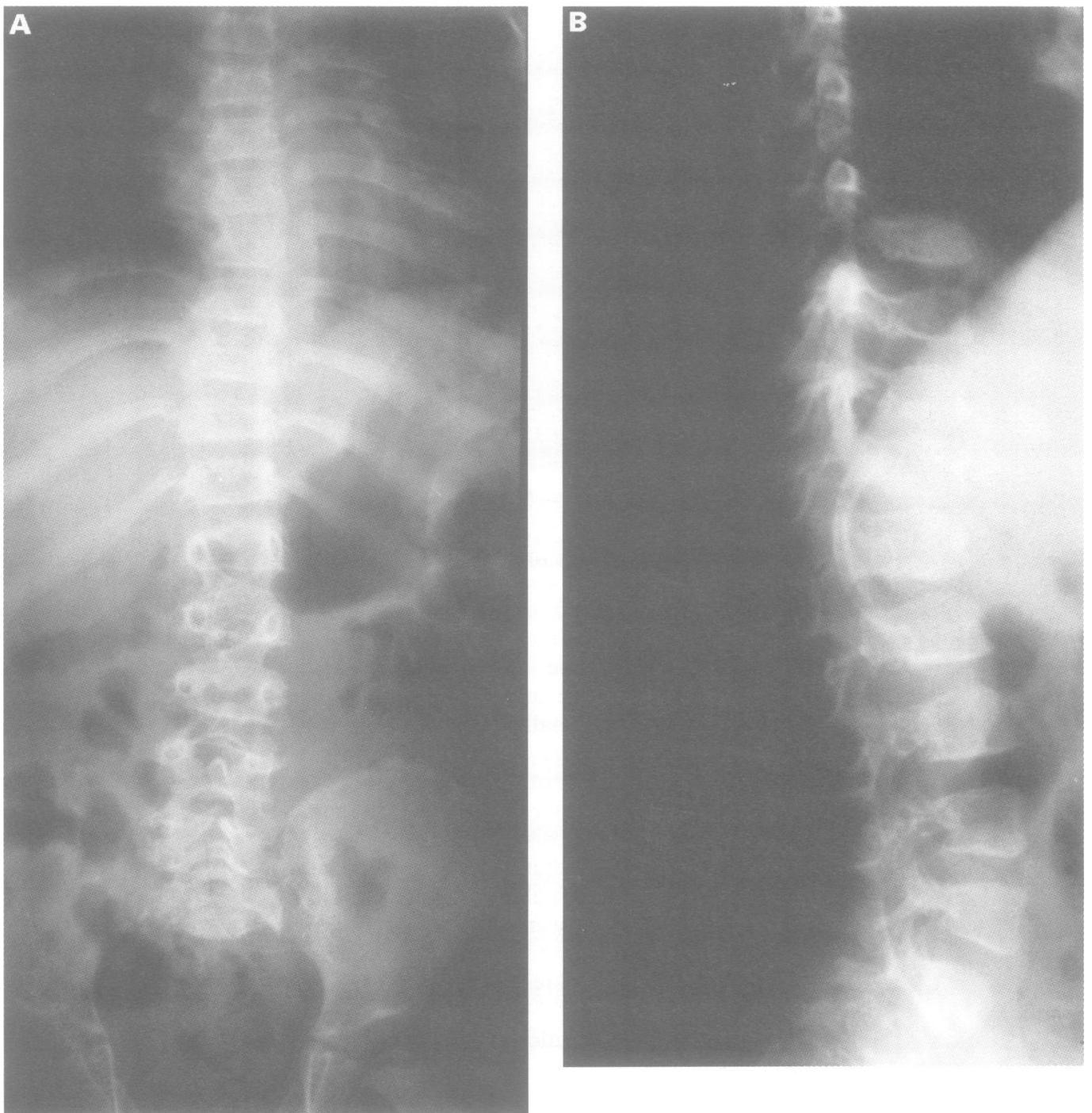

Figure 9 Spine of case 3 aged 4 years. (A) Narrow interpedicular distances. Scoliosis. Spinal dysraphism. (B) Mild kyphosis. Irregular end plates. Pear shaped thoracic vertebral bodies. Posterior and anterior vertebral body scalloping.

vertebral bodies in the lumbar region and some posterior constriction in the thoracic region (fig 9B).

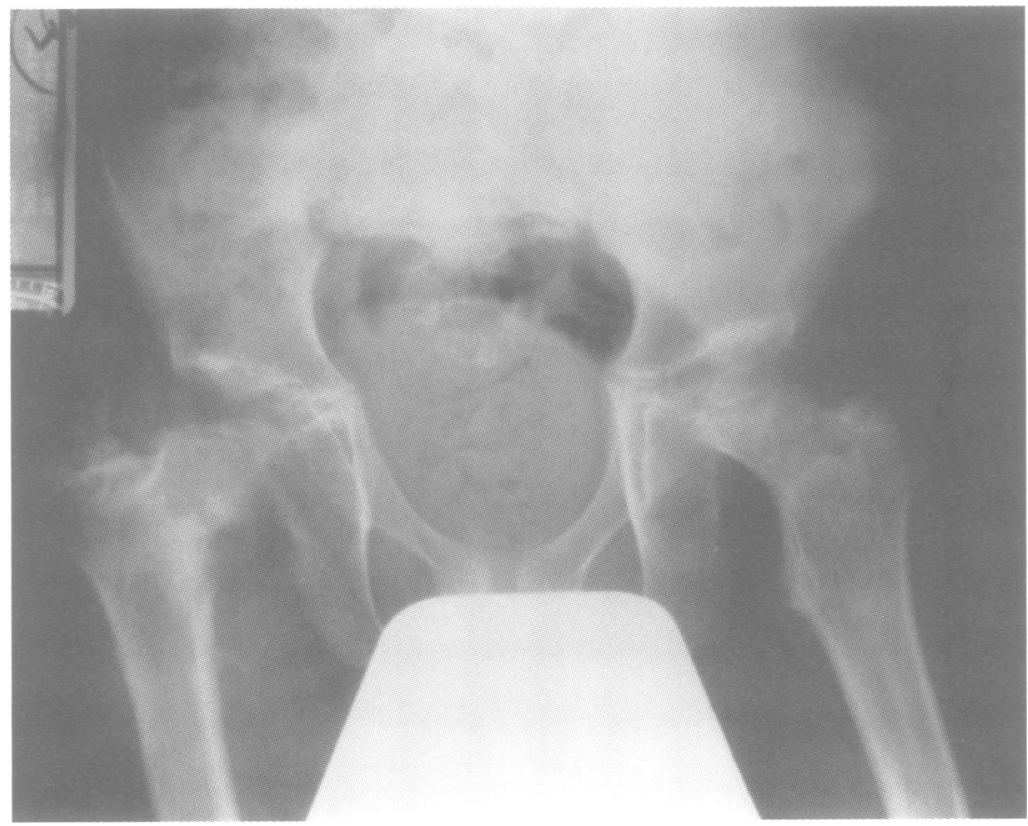

Figure 10 Hips of case 3 aged 10 years. Right coxa vara. Small, flattened capital femoral epiphyses. Mild protrusio acetabulae.
Pelvis. At the age of 4 months, the acetabula were noted to be shallow with bilateral dislocation of the hips. At the age of 3 years, the femoral necks were slender and there was a right coxa vara deformity. The capital femoral epiphyses were small but well located within the acetabula. Subsequently, by the age of 10 years, there was a coarse trabecular pattern throughout and some protrusio acetabulae (fig 10).

Lower limbs. At the age of 3 years there were very mild bowing deformities of the diaphyses of the long bones of the lower limb. The metaphyses were flared and irregular with some streaky sclerosis extending towards the diaphyses. The epiphyses were extremely small, flattened, and irregular with some fragmentation. There was no patellar ossification (fig 11A). By the age of 10 years, the metaphyses were irregular and sclerotic with flattened, irregular, fragmented epiphyses. There was quite marked subluxation and genu valgum deformity on the right. The patella was small and dislocated laterally (fig $11 \mathrm{~B}, \mathrm{C}$ ).

Hands. By 10 years of age, there was marked delay in bone maturation. The metacarpals were slender and the phalanges long with squared distal ends of the proximal and middle phalanges. The tufts of the terminal phalanges 

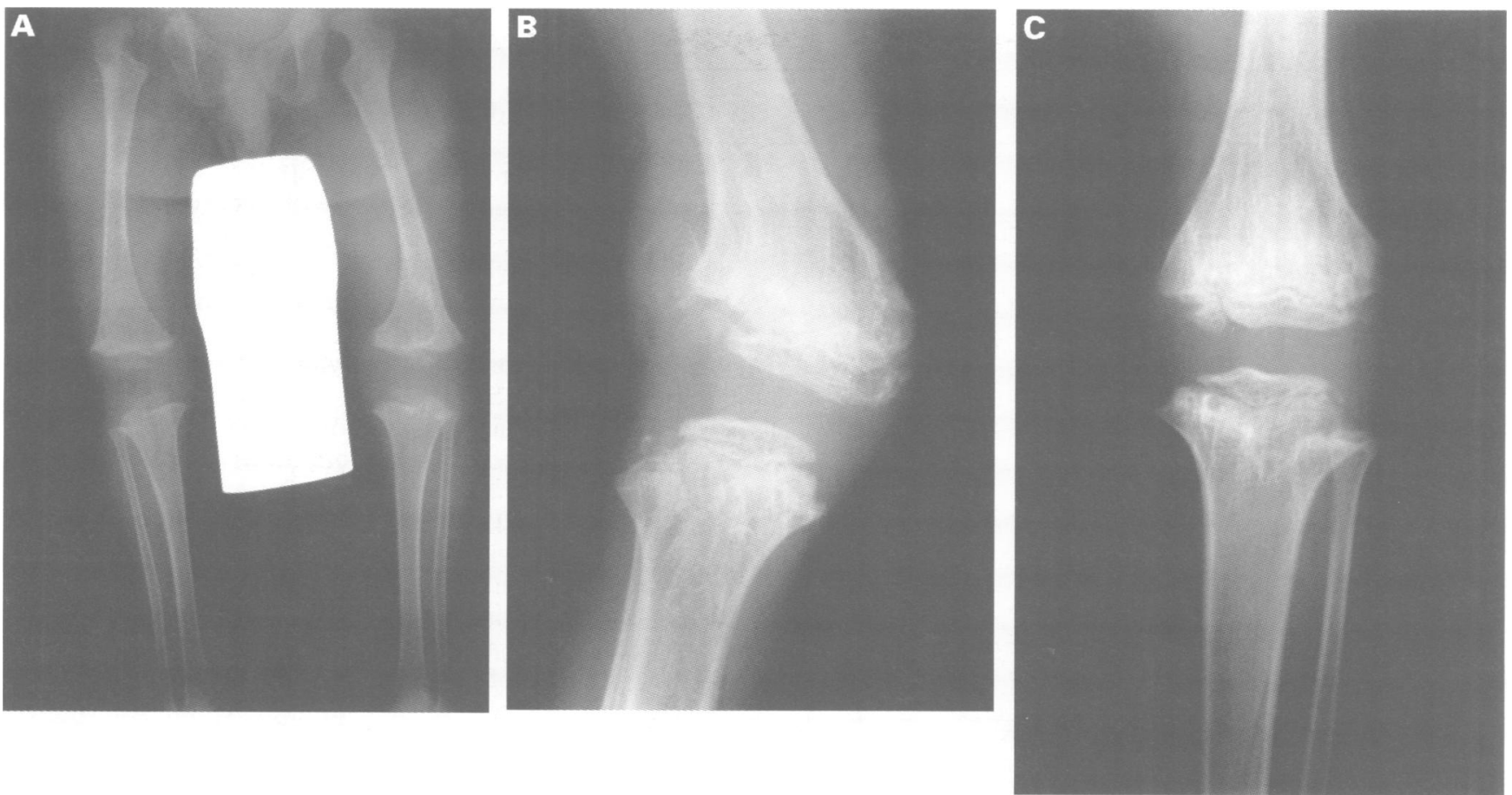

Figure 11 Lower limbs of case 3. (A) Aged 3 years. Narrow femoral necks. Flared and irregular metaphyses with streaky sclerosis. Small flattened irregular epiphyses. Absent patellae. (B, C) Aged 10 years. Right genu valgum with subluxation and dislocated patella. Flattened irregullar small epiphyses. Metaphyses flared and irregular with streaky sclerosis.

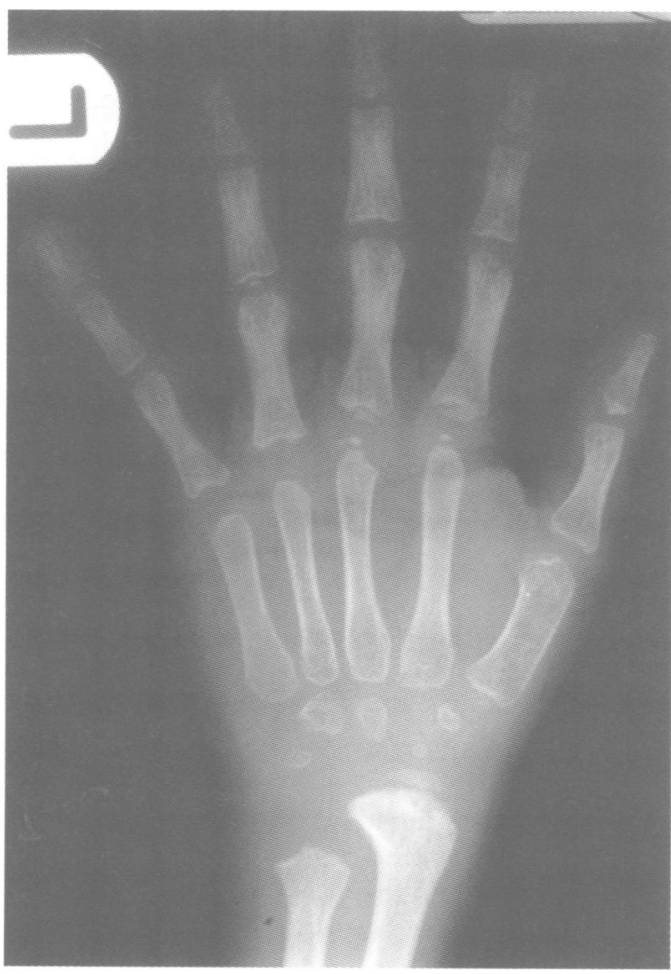

Figure 12 Left hand of case 3 aged 10. Delayed maturation. Slender metacarpals. Squared distal middle phalanges. Small, irregular epiphyses and carpals. Small carpus. Short distal ulna. Prominent distal phalangeal tufts. Irregular, cupped metaphyses.

were prominent. The epiphyses and the carpal centres were small, irregular, sclerotic, and fragmented. The overall size of the carpus was small. All the metaphyses showed irregularity with some cupping. The ulna was short distally (fig 12).

\section{Discussion}

These cases were isolated, in families with unrelated parents, and no relevant family history has been elicited. Chromosome analysis was not undertaken. They all presented in infancy with hip dislocation and joint laxity and developed progressive deformity particularly involving the knees, spine, and hips. Clinically, the facies were normal in two of the three cases with no evidence of ocular or auditory abnormalities. There was no cleft palate and no other significant clinical abnormality. The features of these three children of normal intelligence with short stature included joint laxity with dislocations initially at the hip joints and subsequently the knees with weight bearing. Dislocation of the radial head was present in case 1 . The epiphyses were small, flattened, irregular, and fragmentated. The metaphyses showed widening, irregularity, and streaky sclerosis. The dorsal vertebral bodies showed some posterior decrease in height but appeared more rounded anteriorly and there was scalloping of the posterior aspects of the lumbar vertebral bodies with vertebral end plate irregularity and narrow interpedicular distances. Scolioses developed. The hand changes were particularly characteristic. The metacarpals were gracile, the phalanges long and slender with some squared ends, and the tufts were prominent. The carpal bones were individually small, irregular, and flattened and the overall size of the carpus was reduced. There was gross delay in the appearance of the phalangeal epiphyses. There was absent (severely delayed) ossification of the patellae in all three cases.

Two cases with virtually identical findings have been published previously. One was reported as a case of sponastrime dysplasia by Camera $e t a l^{2}$ and the other by Langer et $a l^{3}$ in a paper describing five new cases of sponastrime dysplasia and differentiating this disorder from both the case of Camera et al and one of their 
Table 1 Clinical and radiological findings of our three cases and the two previously published cases

\begin{tabular}{|c|c|c|c|c|c|}
\hline Features & $\begin{array}{l}\text { Case } \\
1\end{array}$ & $\begin{array}{l}\text { Case } \\
2\end{array}$ & $\begin{array}{l}\text { Case } \\
3\end{array}$ & $\begin{array}{l}\text { Camera } \\
\text { et } \text { al }^{2}\end{array}$ & $\begin{array}{l}\text { Langer } \\
\text { et al }\end{array}$ \\
\hline \multicolumn{6}{|l|}{ Clinical findings } \\
\hline Family history & - & - & - & - & ? \\
\hline Gender & $\mathbf{F}$ & $\mathbf{F}$ & $\mathbf{M}$ & $\mathbf{M}$ & $\mathbf{F}$ \\
\hline Midface hypoplasia & - & + & - & + & + \\
\hline Short stature & + & + & + & + & + \\
\hline Joint laxity & + & + & + & + & ? \\
\hline Dislocations & + & + & + & ? & $?$ \\
\hline $\begin{array}{l}\text { Genu valgum } \\
\text { Radiographic findings }\end{array}$ & + & + & + & + & + \\
\hline Mild scoliosis & + & + & + & + & ? \\
\hline Narrow lumbar IP distances & + & + & + & + & ? \\
\hline Sacral spinal dysraphism & + & + & + & + & ? \\
\hline Lumbar posterior scalloping & + & + & + & + & ? \\
\hline Vertebral end plate irregularity & + & + & + & + & ? \\
\hline Hip subluxation/dislocation & + & + & + & - & ? \\
\hline Slender femoral necks & + & + & + & + & + \\
\hline Small irregular epiphyses & + & + & + & + & + \\
\hline Metaphyseal irregularity, sclerosis, striations & + & + & + & + & + \\
\hline Delayed bone maturation & + & + & + & + & + \\
\hline Delayed patellar ossification & + & + & + & + & + \\
\hline Gracile metacarpals & + & + & + & + & + \\
\hline Small carpus & + & + & + & + & + \\
\hline Small carpal bones & + & + & + & + & + \\
\hline Squared distal ends of middle phalanges & + & + & + & + & + \\
\hline
\end{tabular}

own. Langer $e t a l^{\beta}$ also stated that they had seen six cases with this particular type of SEMD. The salient clinical and radiological findings of our cases and the two previously reported are shown in table 1.

Confusion with sponastrime dysplasia arises because of the short stature and sclerotic longitudinal striations seen at the metaphyses of the knees in both conditions. However, our cases show striking epiphyseal changes, specific hand findings, and joint laxity with dislocations. In addition, the spinal changes are quite distinct with narrow interpedicular distances and posterior scalloping.

Other conditions from the large heterogeneous group of SEMDs require differentiation. Taybi and Lachman ${ }^{1}$ have classified the SEMDs and identified common and rare forms. Our cases are classified as rare with the designation "SEMD with large joint dislocations". The other form with joint laxity and dislocations is "SEMD with joint laxity (SEMD-JL)". This is classified as one of the more commonly described forms and was first reported by Beighton and Kozlowski in $1980^{4}$ and later expanded in $1983,{ }^{5} 1984,{ }^{6}$ and $1994 .{ }^{7}$ These have mainly, but not exclusively, been reported from the South African Afrikaans population with most families being of Dutch or German descent and inheritance is autosomal recessive. The kyphoscoliosis is present at birth and progresses to severe deformity, sometimes with cardiorespiratory compromise, during early childhood, unlike the mild kyphoscolioses identified in our cases. Additional features include talipes, cleft palate, congenital heart disease, and specific facial dysmorphism. The typical radiological findings in the spine and hands in our patients are not seen in SEMD-JL.

Other conditions with spondyloepimetaphyseal changes include SEMD type Strudwick, spondyloepiphyseal dysplasia congenita, and Stickler syndrome, all identified as resulting from type 2 collagen mutations. In addition, otospondylometaepiphyseal dysplasia (OSMED) and some Stickler-like disorders have been identified as type 11 collagen disorders. These conditions all have dysmorphic features similar to three of the five cases of SEMD with multiple dislocations with midface hypoplasia.

Families with overlapping features of pseudoachondroplasia and multiple epiphyseal dysplasia are caused by COMP mutations and some of these, together with some families with the severe form of multiple epiphyseal dysplasia (type Fairbank), have type 9 collagen mutations.

Given the increasing evidence of allelic disorders in the skeletal dysplasias it will be interesting to see whether SEMD with multiple dislocations is caused by specific mutations in type 2 or 11 collagen genes or COMP or in a similar gene.

We have described a new form of SEMD in three unrelated sporadic cases and identified two additional published cases. The term "SEMD with multiple dislocations" is used to differentiate this condition from the well delineated autosomal recessive disorder of SEMDJL. Further reports will help towards a better understanding of the nosology of this disorder.

The authors express their thank to Drs Helen M Carty, Steven Chapman, and Robert F Mueller for referral of the patients.

1 Taybi H, Lachman RS, eds. Radiology of syndromes, metabolic disorders, and skeletal dysplasias. 4th ed. St Louis: Mosby, 1996:916-23.

2 Camera G, Camera A, Pozzolo S, Costa P. Sponastrime dysplasia: report on a male patient. Pediatr Radiol 1994;24: 322-4.

3 Langer LO Jr, Beals RK, Scott CI Jr. Sponastrime dysplasia: diagnostic criteria based on five new and six previously published cases. Pediatr Radiol 1997;27:409-14.

4 Beighton P, Kozlowski K. Spondylo-epi-metaphyseal dysplasia with joint laxity and severe, progressive kyphoscoliosis. Skeletal Radiol 1980;5:205-12.

5 Beighton P, Gericke G, Kozlowski K, Grobler L. Spondyloepimetaphyseal dysplasia with joint laxity and severe, progressive kyphoscoliosis. $S$ Afr Med $\mathcal{F} 1983 ; 64: 772-5$.

6 Beighton P, Kozlowski K, Gericke G, Wallis G, Grobler L. The manifestations and natural history of spondylo-epimetaphyseal dysplasia with joint laxity. Clin Genet $1984 ; 26$ : metaphysea

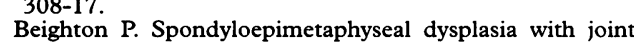
laxity (SEMDJL). $\mathcal{F}$ Med Genet 1994;31:136-40. 